\title{
Proteomics analysis of melanoma metastases: association between S100A13 expression and chemotherapy resistance
}

\author{
A Azimi ${ }^{1,3}$, M Pernemalm ${ }^{2,3}$, M Frostvik Stolt $^{1}, \mathrm{~J} \mathrm{Hansson}^{1}, \mathrm{~J} \mathrm{Lehtiö}^{2}, \mathrm{~S}$ Egyházi Brage ${ }^{1}$ \\ and C Hertzman Johansson*,1 \\ ${ }^{1}$ Department of Oncology-Pathology, Karolinska Institutet, CCK R8:03, Karolinska University Hospital, Solna, S-17176 Stockholm, \\ Sweden and ${ }^{2}$ Department of Oncology-Pathology, Karolinska Institutet, Science for Life Laboratory, Tomtebodavägen 23, S-17165 \\ Solna, Sweden
}

Background: Disseminated cutaneous malignant melanoma (CMM) is commonly unresponsive to standard chemotherapies, and there are as yet no predictive markers of therapy response.

Methods: In the present study we collected fresh-frozen pretreatment lymph-node metastasis samples $(n=14)$ from melanoma patients with differential response to dacarbazine (DTIC) or temozolomide (TMZ) chemotherapy, to identify proteins with an impact on treatment response. We performed quantitative protein profiling using tandem mass spectrometry and compared the proteome differences between responders (R) and non-responders (NR), matched for age, gender and histopathological type of CMM.

Results: Biological pathway analyses showed several signalling pathways differing between $\mathrm{R} v \mathrm{NR}$, including Rho signalling. Gene expression profiling data was available for a subset of the samples, and the results were compared with the proteomics data. Four proteins with differential expression between R and NR were selected for technical validation by immunoblotting (ISYNA1, F13A1, CSTB and S100A13), and CSTB and S100A13 were further validated on a larger sample set by immunohistochemistry $(n=48)$. The calcium binding protein S100A13 was found to be significantly overexpressed in NR compared with R in all analyses performed.

Conclusions: Our results suggest that S100A13 is involved in CMM resistance to DTIC/TMZ.

Cutaneous malignant melanoma (CMM) is one of the most aggressive skin cancer types, with a rapid increase in prevalence, especially among western countries (Erdmann et al, 2013). So far, curative treatment is achieved only by surgical resection of primary tumours at an early stage (Balch et al, 2001; Balch et al, 2004). Chemotherapy with the alkylating agents dacarbazine (DTIC) and temozolomide (TMZ) has not shown any effect on median overall survival of patients (Hill et al, 1984; Gogas et al, 2007). However, $\sim 13 \%$ of the patients have an initial partial or complete response to these drugs and rare long-time responses are seen (Middleton et al, 2000; Kim et al, 2010; Patel et al, 2011). Several chemoresistance mechanisms have been proposed, but the clinically relevant mechanisms are to a large extent still unknown.

DNA repair proteins, such as O-6-methylguanine-DNA methyltransferase (MGMT), which counteract the alkylating effects of DTIC/TMZ, have been suggested to confer resistance to these drugs (for a review, refer to the study by Zhang et al (2012)). The relationship between MGMT and response to therapy has mainly been reported for TMZ treatment in glioma, but association between MGMT expression and resistance to DTIC/TMZ has been found also in melanoma (Ma et al, 2003; Busch et al, 2010). In addition, studies using melanoma cell lines have suggested a role

\footnotetext{
*Correspondence: Dr C Hertzman Johansson; E-mail: carolina.johansson@ki.se

${ }^{3}$ These authors contributed equally to this work.
}

Revised 1 March 2014; accepted 5 March 2014; published online 10 April 2014

(C) 2014 Cancer Research UK. All rights reserved 0007 - 0920/14 
for melanosomes and related protein-trafficking pathways in melanoma chemoresistance (Chen et al, 2006; Xie et al, 2009), and we have shown higher expression of the key melanogenesis regulator microphthalmia-associated transcription factor (MITF) and the melanosomal G-protein-coupled receptor 143 (GPR143) in tumours from non-responders to DTIC/TMZ therapy, compared with responders (Hertzman Johansson et al, 2013).

Recently, the treatment options for melanoma have expanded rapidly, and several novel immunotherapies and small-molecule drugs targeting the MAPK pathway have been approved or are in clinical trials (Hodi et al, 2010; Chapman et al, 2011; Hauschild et al, 2012; Flaherty et al, 2012a,b; Menzies and Long, 2013). Unfortunately, primary resistance is widely encountered for immunotherapies, and despite many impressive initial responses to MAPK signalling inhibitors, acquired drug resistance eventually develops. Thus, chemotherapy could have a role in combination therapies by inhibiting the growth of tumour cells that are resistant to specific inhibitors. In addition, standard chemotherapy is still relevant for patients not responding to immunotherapy, and for those whose tumours lack activated druggable targets.

To identify proteins associated with chemotherapy resistance, we carried out protein expression profiling of tumour biopsies from patients with differential response to DTIC/TMZ treatment. Gene expression profiling data was available for a majority of the tumours (Hertzman Johansson et al, 2012), and several candidate genes and biological pathways were identified by both methods. Four of the top candidates among the identified proteins were validated in the same tumour samples by immunoblotting. In addition, two of the candidate proteins with higher expression in non-responders, the calcium binding protein S100A13 and the cathepsin inhibitor cystatin B (CSTB), were further studied by immunohistochemistry in an extended set of pre-treatment tumour samples. The significantly higher expression of S100A13 in non-responders was confirmed also in this sample set.

\section{MATERIALS AND METHODS}

Tumour samples. Fresh-frozen pre-treatment lymph-node biopsies were excised from patients with metastatic cutaneous melanoma before chemotherapy with DTIC/TMZ. All tumour pieces included had a tumour cell burden of at least $50 \%$ (the majority of tumours $>70 \%$ ). Although there were individual differences between the tumour pieces with regard to cell composition, vascularisation and infiltration of leukocytes, there were no major differences between the groups of responders and non-responders (see Supplementary Figure 1 for histological images).

Five patients were responders (defined as a reduction of tumour size of at least 50\%), and five non-responders (with stable or progressive disease) were matched to the responders with regard to gender, histopathology (superficial spreading or nodular melanoma) and, when possible, age. Four of the responders had previously been included in a gene expression profiling study (Hertzman Johansson et al, 2012) and four non-responders from this study material were also included in the present analysis, in addition to the five matched non-responders. For details on the clinical material included in the proteomics analysis, see Supplementary Table 1 and Supplementary Figure 1.

For the immunohistochemistry, an extended material of formalin-fixed paraffin-embedded pre-treatment biopsies from 16 DTIC/TMZ responders and 34 non-responders were analysed.

Patients have given informed consent and the study was approved by the Regional Ethics Committee of Stockholm.

Protein sample preparation. Tissue disruption was performed using a Mixer mill MM200 (Retsch, Haan, Germany) with a $1-\mathrm{cm}$ $\varnothing$ Teflon-coated tungsten ball. Teflon vials, caps and the ball were first pre-cooled in $-80^{\circ} \mathrm{C}$ and then in liquid nitrogen. Frozen tumour samples $(\sim 3 \times 3 \times 3 \mathrm{~mm})$ were cut into smaller pieces $(1 \times 1 \times 1 \mathrm{~mm})$ on a block of dry ice. Samples were then transferred to the pre-cooled vials and cooled again for $2 \mathrm{~min}$ in liquid nitrogen. The samples were then homogenised in the Mixer mill for 2 min at maximum speed after which they were put back into the liquid nitrogen. This homogenisation/cooling procedure was repeated three times until a frozen tumour powder was achieved. The powder was dissolved in $1 \mathrm{ml} 20 \mathrm{~mm}$ HEPES ( $\mathrm{pH}$ 7.6), transferred to Eppendorf tubes and kept in $-80^{\circ} \mathrm{C}$.

The samples were thawed and DTT and SDS were added to an end concentration of $1 \mathrm{~mm}$ and $3.75 \%$, respectively. Samples were then lysed by heating (at $90{ }^{\circ} \mathrm{C}$ for $5 \mathrm{~min}$ on a thermomixer) and sonication (at room temperature for $5 \mathrm{~min}$ ). The samples were then centrifuged at $10000 \mathrm{~g}$ for $10 \mathrm{~min}$ and the supernatant was transferred to a new tube. Protein concentrations of the lysates were measured using the DC protein assay kit 2 (BioRad, Hercules, CA, USA). The protein yield was at least $1.6 \mathrm{mg}$ per tumour piece.

For acetone precipitation, $120 \mathrm{mg}$ of protein from each sample was mixed with four volumes of ice-cold acetone. The samples were incubated in $+4{ }^{\circ} \mathrm{C}$ for 2 hours until a flocculent formed. The samples were then centrifuged for $10 \mathrm{~min}$ at $10000 \mathrm{~g}$. The supernatant was discarded and the protein was allowed to air dry. This step was performed for the MS/MS analysis, but not for immunoblotting samples.

Digestion, iTRAQ labelling and clean-up of protein samples. Samples were digested and labelled according to a standard iTRAQ eight-plex protocol (Thermo Fisher Scientific, Waltham, MA, USA). The trypsin-to-protein ratio was $1: 20$. One hundred micrograms of each sample were labelled and two pools were made each with seven samples and one internal standard for normalisation.

Pooled iTRAQ-labelled digests were applied to $1 \mathrm{ml}$ Strata X-C $33 \mu \mathrm{m}$ polymeric strong cation exchange (SCX) microcolumns (Phenomenex, Torrance, CA, USA). The microcolumns were

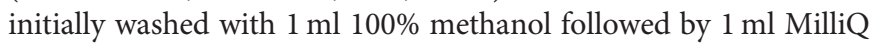
grade water (EMD Millipore Corporation, Billerica, MA, USA). The sample was adjusted to $500 \mu \mathrm{l} 0.1 \%$ formic acid and then applied to the columns. After washing with $1 \mathrm{ml} 30 \%$ methanol and $0.1 \%$ formic acid the samples were eluted with $30 \%$ methanol and $5 \%$ ammonium hydroxide. Samples were then dried in a SpeedVac system (EMD Millipore Corporation).

Narrow-range IEF. Briefly, samples were added to $\mathrm{pH} 3.3$ loading strips, kindly provided by GE healthcare (Uppsala, Sweden), and allowed to re-swell overnight. Loading strips were then put on re-swelled 24-cm narrow-range isoelectric focusing strips ( $\mathrm{pH} 3.4-4.7$ ) also provided by GE Healthcare. Samples were focused until $100 \mathrm{kVhs}$ was reached. The peptides were passively eluted in 72 fractions of $150 \mu \mathrm{l}$ milliQ water using an in-house robot. Eluted peptide samples were then dried in a SpeedVac system.

Mass spectrometry. The 72 fractions were re-suspended in $10 \mu \mathrm{l}$ of $3 \%$ acetonitrile in $0.1 \%$ formic acid. From each IPG fraction $3 \mu$ l was injected into online HPLC/MS performed on a hybrid LTQ-Orbitrap Velos mass spectrometer (Thermo Fischer Scientific, San Jose, CA, USA). An Agilent HPLC 1200 system (Agilent Technologies, Santa Clara, CA, USA) was used to provide the gradient for online reversed-phase nano-LC at a flow of $0.4 \mu \mathrm{lmin}{ }^{-1}$. Solvent A was $97 \%$ water, $3 \% \mathrm{ACN}$ and $0.1 \%$ formic acid, and solvent B was $5 \%$ water, $95 \% \mathrm{ACN}$ and $0.1 \%$ formic acid. The curved gradient went from $2 \%$ B up to $40 \%$ B in $45 \mathrm{~min}$, followed by a steep increase to $100 \% \mathrm{~B}$ in $5 \mathrm{~min}$. The sample was injected into a $\mathrm{C} 18$ guard-desalting column (Agilent Technologies) prior to a $15 \mathrm{~cm}$ long C18 picofrit column $(100 \mu \mathrm{m}$ internal diameter, $5 \mu \mathrm{m}$ bead size, Nikkyo Technos Co., Tokyo, Japan) installed on to the nano electrospray ionisation (NSI) source of the Orbitrap Velos instrument (Thermo Fisher, Waltham, MA, USA). Acquisition proceeded in 
23.5-s scan cycles, starting by a single full-scan MS at 30000 resolution (profile mode), followed by two stages of data-dependent tandem MS (centroid mode): the top five ions from the full scan MS were selected first for collision-induced dissociation (CID, at 35\% energy) with $\mathrm{MS} / \mathrm{MS}$ detection in the ion trap, and finally for higherenergy collision dissociation (HCD, at $45 \%$ energy) with MS/MS detection in the orbitrap. Precursors were isolated with a $2 \mathrm{~m} / z$ width and dynamic exclusion was used with $60 \mathrm{~s}$ duration.

Database search. Orbitrap data was searched by Mascot 2.2 (Matrix Science Limited, London, UK) under the software platform Proteome Discoverer 1.1 (Thermo) against the human Uniref100 protein sequence database. A precursor mass tolerance of 10 p.p.m., and product mass tolerances of $0.02 \mathrm{Da}$ for HCD-FTMS and $0.8 \mathrm{Da}$ for CID-ITMS were used. Further settings used were the following: trypsin with 1 missed cleavage; carbamidomethylation on cysteine and iTRAQ-8plex on lysine and N-terminal as fixed modifications; and oxidation of methionine as variable modification. Quantification of iTRAQ-8plex reporter ions was performed by using Proteome Discoverer on HCD-FTMS tandem mass spectra using an integration window tolerance of 20 p.p.m. In total, 5873 proteins were identified with $\geqslant 1$ peptide $95 \%$ confidence. Out of these 3029 proteins were significantly $(95 \%$ confidence) detected in both of the sample pools. The downstream data analysis was performed on these 3029 overlapping proteins (for details, see Supplementary Table 2).

Immunoblotting. For technical validation of selected biomarker candidates, the same tumour protein extracts as in the protein profiling were analysed by immunoblotting, using NuPAGE Novex Bis-Tris Gel (Life Technologies, Carlsbad, CA, USA) and PVDF membranes (Thermo Scientific, Rockford, IL, USA), according to the manufacturer's standard protocol and the following primary antibodies from Sigma Aldrich Sweden AB (Stockholm, Sweden): ISYNA1 produced in rabbit $(1: 500$; catalogue no. AV53716); CSTB produced in mouse $(1: 1000$. catalogue no. C5243); F13A1 antibody produced in rabbit $(1: 250$; catalogue no. HPA001804); S100A13 produced in rabbit $(1: 250$. catalogue no. HPA019592); and $\beta$-actin produced in mouse $(1: 5000$; catalogue no. A544). The primary antibody for $\beta$-tubulin (sc-9104 from Santa Cruz Biotechnology, Inc., Santa Cruz, CA,, USA) was diluted 1:200. The HRP-conjugated secondary antibodies used were bovine antirabbit antibody (1: 1000; Santa Cruz Biotechnology catalogue no. SC2379) and goat anti-mouse antibody (1:2000; Life Technologies catalogue no. 626520). The Pierce ECL Western Blotting Substrate (Thermo Scientific) was used for detection. Quantification of the protein expression was performed using Image J (http://rsbweb.nih. gov/ij/index.html)

Immunohistochemistry. Immunohistochemistry was performed on formalin-fixed, paraffin-embedded $3-4 \mu \mathrm{m}$ thick tumour sample sections. Antigen retrieval was induced by heating the sections in humid decloaking heat chambers (Biocare, Concord, CA, USA) in citrate buffer ( $\mathrm{pH}$ 6.0) according to the manufacturer's instruction followed by $10 \mathrm{~min}$ incubation with $3 \%$ hydrogen peroxide at room temperature and washing with $1 \times$ TBS buffer. To avoid unspecific binding, the sections were incubated with $2.5 \%$ horse serum for $20 \mathrm{~min}$ at room temperature followed by overnight incubation at $4{ }^{\circ} \mathrm{C}$ with primary antibodies against CSTB (1:1000 Sigma Aldrich Sweden AB catalogue no. C5243) or S100A13 (1:750 Sigma Aldrich Sweden AB catalogue no. HPA019592) in TBS buffer containing 1.5\% horse serum. Negative controls were incubated with the same TBS buffer without any primary antibody.

Incubation with the secondary antibody plus streptavidin/ peroxidase was performed according to the manufacturer's instructions (Vectastain Universal Quick Kit, Vector Laboratories Inc., Burlingame, CA, USA) and were developed with 3,3'-diaminobenzidine (DAB Kit, Vector Laboratories Inc.). As the final step, slides are rinsed in water and counterstained with Mayer's haematoxylin, rinsed with water, dehydrated and sealed with glass lamella and mounting solution Mountex (Histolab, Spånga, Sweden).

Independent assessment of all slides was performed by at least three observers (AA, CHJ, MFS or SEB). The intensity was scored $0-3(0=$ no staining, $1=$ weak, $2=$ moderate, $3=$ strong staining $)$ and samples where $>30 \%$ of the tumour cells had an intensity score of at least 2 were considered to have positive staining.

Immunohistochemistry for ISYNA1 and F13A1 was not completed due to unspecific staining for the antibodies available.

Statistical analysis. Quality assessment of the LC/MS/MS data was done using principal component analysis (PCA) to check for outliers (SIMCA statistical analysis software, Umetrics, Umeå, Sweden). Multivariate orthogonal-partial least squares (O-PLS) analysis was performed, also using SIMCA. For optimisation of O-PLS models we used VIP (Variable Importance in Projection) value to judge protein importance in the model. The O-PLS models were validated by sevenfold cross validation. Proteins with significant VIP throughout the cross validation of the model were selected for the optimised model. CV-ANOVA was used to judge the model validity (Eriksson et al, 2004). Biological pathways analyses were performed using the Ingenuity IPA software (Ingenuity Systems, Qiagen, Redwood City, CA, USA).

For the immunohistochemistry results, Fisher's exact test was used to analyse the difference in S100A13 and CSTB protein expression between responders and non-responders.

\section{RESULTS}

Mass spectrometry. Fourteen fresh-frozen melanoma lymphnode metastasis samples (see Supplementary Table 1), from five chemotherapy responders and nine non-responders, were profiled by liquid chromatography tandem mass spectrometry (LC/MSMS). In total, 3029 proteins were detected in all samples, and the downstream data analyses were performed on this data set. Detailed protein data are provided in Supplementary Table 2. To check for outliers, unsupervised assessment was performed using PCA and no significant outlier was identified. Multivariate O-PLS was performed to create models that could separate the responders and non-responders.

A significant O-PLS model consisting of ninety-four proteins was created when comparing pretreatment tumours from five responders and five non-responders that were matched for age, gender and histopathological type (CV-ANOVA, $P=0.0007$, $\mathrm{Q} 2=0.874, \mathrm{R} 2 \mathrm{Y}=0.906$ and $\mathrm{R} 2 \mathrm{X}=0.619$, see Supplementary Table 3). The enriched top molecular and cellular functions and canonical pathways of this selected group of 94 proteins was defined by ingenuity pathway analysis (see Table 1), and include several key cell signalling pathways such as Rho and Rac signalling.

For four of the responders in the present study, gene expression profiling data from the same tumours were available (Hertzman Johansson et al, 2012). The proteomic results from these samples and four other (unmatched) non-responders, which were also included in the gene expression profiling study, were analysed separately with the purpose of comparing the differences on protein level to the transcriptome data (see Supplementary Table 1 for details regarding the samples included). An O-PLS model consisting of 146 proteins was created (CV-ANOVA $P=0.006$, $\mathrm{Q} 2=0.998, \quad \mathrm{R} 2 \mathrm{Y}=1$ and $\mathrm{R} 2 \mathrm{X}=0,783$, see Supplementary Table 3). Compared with the first O-PLS model, with the matched non-responders, 11 proteins overlapped and 76 canonical pathways were identified in both models (see Supplementary Table 3). 
When comparing the proteomics results to the transcriptome data for the samples where this was available, 13 candidates were identified by both methods, 6 with concordant expression levels (see Table 2 for details). We could also detect 16 overlapping biological pathways in the gene expression profiling and the corresponding proteomics study (see Supplementary Table 4). Four of these pathways were immune system-related, and the remaining 12 were signalling cascades, including actin cytoskeleton signalling, RhoA signalling, PPAR signalling and IL-8 signalling.

The proteins in the two O-PLS models were also compared with known targets of the transcription factor MITF (Hoek et al, 2008; Strub et al, 2011), a potential chemoresistance candidate (Hertzman Johansson et al, 2013). About 40\% of the proteins identified in the present study are previously reported to be regulated by MITF (see Supplementary Table 3 for details).

Immunoblotting. Four of the identified chemotherapy response candidates, CSTB, F13A1, ISYNA1 and S100A13, were selected for technical validation by immunoblotting, using the same protein extract as in the MS analyses. The selection was based on the strength of the proteomics and gene expression profiling results, as well as the biological function of the protein. Among the proteins that were

Table 1. Top cellular and molecular functions and canonical pathways identified when comparing the tumour proteome profile of pre-treatment biopsies from five DTIC/TMZ responders and five matched nonresponders

\begin{tabular}{|l|c|}
\hline Top cellular and molecular functions & $P$-value \\
\hline RNA post-transcriptional modification & $1.10 \mathrm{E}-05-3.29 \mathrm{E}-02$ \\
\hline Cell morphology & $2.22 \mathrm{E}-04-3.75 \mathrm{E}-02$ \\
\hline Cell-to-cell signalling and interaction & $2.22 \mathrm{E}-04-3.75 \mathrm{E}-02$ \\
\hline Carbohydrate metabolism & $3.32 \mathrm{E}-04-3.75 \mathrm{E}-02$ \\
\hline Cellular movement & $3.47 \mathrm{E}-04-3.75 \mathrm{E}-02$ \\
\hline Top canonical pathways & \\
\hline Signalling by Rho Family GTPases & 0.000108 \\
Actin nucleation by ARP-WASP complexes & 0.000145 \\
Rac signalling & 0.00147 \\
fMLP signalling in neutrophils & 0.00175 \\
Clathrin-mediated endocytosis signalling & 0.00189 \\
\hline
\end{tabular}

investigated further, F13A1 and S100A13 were among the top 10 most upregulated in non-responders in the proteomics analysis of the matched samples (see Supplementary Table 3). F13A1 activation is the last event in the blood coagulation cascade and high abundance of the protein is expected in an advanced tumour with the hallmark of blunt and leaky vessels. Presence of high levels of this coagulation factor in the tumours can also lead to more blood clotting events in the tumour vessels and consequently, less efficiency in drug penetration in inner layers of the metastasis. S100A13 is suggested to have a role in melanoma progression and angiogenesis (Massi et al, 2010), and calcium-binding proteins, including S100A13, have been reported to be elevated in cisplatin-resistant melanoma cell lines in a recent proteomics study (Paulitschke et al, 2013).

The two other selected candidates, CSTB and ISYNA1, had been identified by both proteome and gene expression profiling and showed similar results in both analyses (see Table 2). The three selected candidates with higher expression in resistant tumours, CSTB, F13A1 and S100A13, have all been reported to be targets of MITF (Hoek et al, 2008; Strub et al, 2011).

All four proteins analysed showed similar results in the proteomics and immunoblotting analyses (see Figure 1), thereby confirming the quantitative proteomics analysis.

Immunohistochemistry. To evaluate the clinical relevance of the identified chemoresistance candidates we performed immunohistochemistry on an extended set of tumours from 16 responders and 32-34 non-responders. The antibodies for ISYNA1 and F13A1 were tested, but did not work well for immunohistochemistry and were not included in this analysis. Representative images of CSTB and S100A13 staining are shown in Figure 2.

Analysis of the cytoplasmic expression showed that, similar to the proteomics results, significant S100A13 staining was more often found in non-responders compared with responders $(P=0.013)$, while CSTB did not deviate between the groups (see Table 3). No difference in nuclear expression was observed for either protein (data not shown).

\section{DISCUSSION}

The aim of the present study was to unravel a protein signature predictive of the efficacy of DTIC/TMZ therapy in pre-treatment

Table 2. Candidates identified as differentially expressed in DTIC/TMZ responders and non-responders by both proteomics and gene expression profiling

\begin{tabular}{|c|c|c|c|c|}
\hline $\begin{array}{l}\text { Protein } \\
\text { accession }\end{array}$ & Symbol & Protein name & $\begin{array}{l}\text { Proteomics GE } \\
\text { profiled samples }\end{array}$ & $\begin{array}{c}\text { Gene expression } \\
\text { profiling }\end{array}$ \\
\hline Q9Y2Q5 & ROBLD3 & Roadblock domain containing 3 & -1.2 & 0.8 \\
\hline P59998 & ARPC4 & Actin-related protein $2 / 3$ complex, subunit 4 & -0.8 & 0.4 \\
\hline P07203 & GPX1 & Glutathione peroxidase & -0.6 & 0.9 \\
\hline Q2NLC8 & GSTK1 & Glutathione S - transferase kappa 1 & -0.6 & 0.7 \\
\hline P04080 & CSTB & Cystatin B (stefin B) & -0.5 & -1 \\
\hline Q6FG43 & FLOT2 & Flotilin 2 & -0.5 & 0.7 \\
\hline B4DN37 & DEK & DEK oncogene & -0.4 & 0.5 \\
\hline P62136 & PPP1CA & Protein phosphatase 1, catalytic subunit, alpha isoenzyme & -0.4 & 1.4 \\
\hline B4DJ89 & POLR2E & Polymerase (RNA) II (DNA-directed) polypeptide E & 0.2 & 0.9 \\
\hline A2RRE5 & GRLF1 & Glucocorticoid receptor DNA binding factor 1 & 0.4 & 0.7 \\
\hline Q96G21 & IMP4 & IMP4, U3 small nucleolar ribonucleoprotein & 0.5 & 0.6 \\
\hline B4E1U1 & PITPNA & Phosphatidylinositol transfer protein, alpha & 0.6 & 0.9 \\
\hline B7Z3K3 & ISYNA & Inositol-3-phosphate synthase 1 & 1.4 & 1.2 \\
\hline
\end{tabular}


A

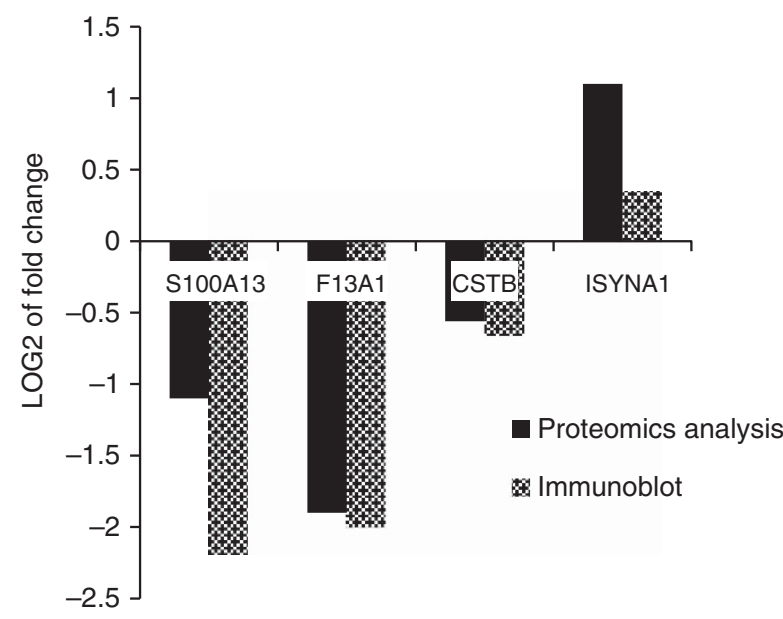

B

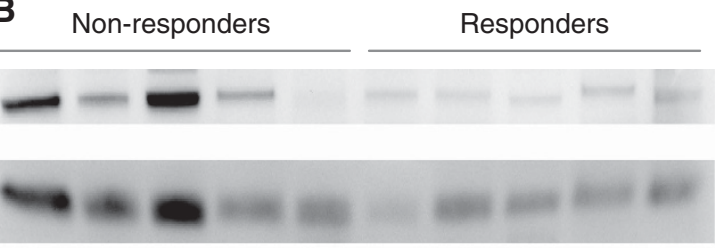

$\mathrm{F} 13 \mathrm{~A} 1$

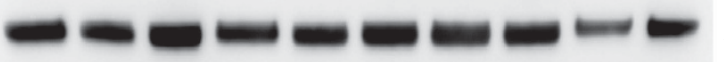

$\beta$-Actin
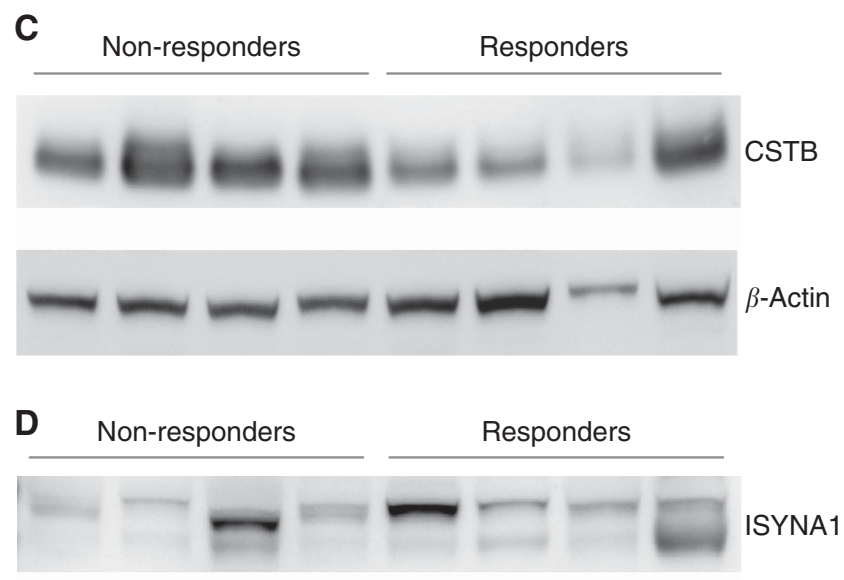

ISYNA1

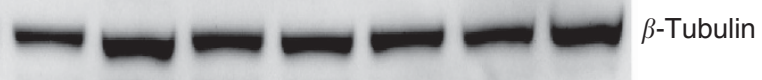

Figure 1. Immunoblot results. (A) Comparison of proteomics and immunobloting results. Data are shown as the log2 of the mean of the fold change in responders over the value in non-responders. (B-D) Immunoblot images for four candidate proteins.

melanoma tumour biopsies, using mass spectrometry-based proteomics. We compared the proteome profile of tumour samples from chemotherapy non-responders with that of responders. For four of the identified proteins (the cathepsin inhibitor cystatin B (CSTB), myo-inositol 1-phosphate synthase (ISYNA1, that catalyses the de novo synthesis of inositol 1-phosphate from glucose 6-phosphate), the coagulation factor F13A1 and the calcium binding protein S100A13) the expression differences between tumours from responders and non-responders were validated by immunoblotting, indicating the robustness of the MS analysis.

To our knowledge, this is the first LC/MS-MS study of drug resistance in human melanoma tumours. Resistance to TMZ and
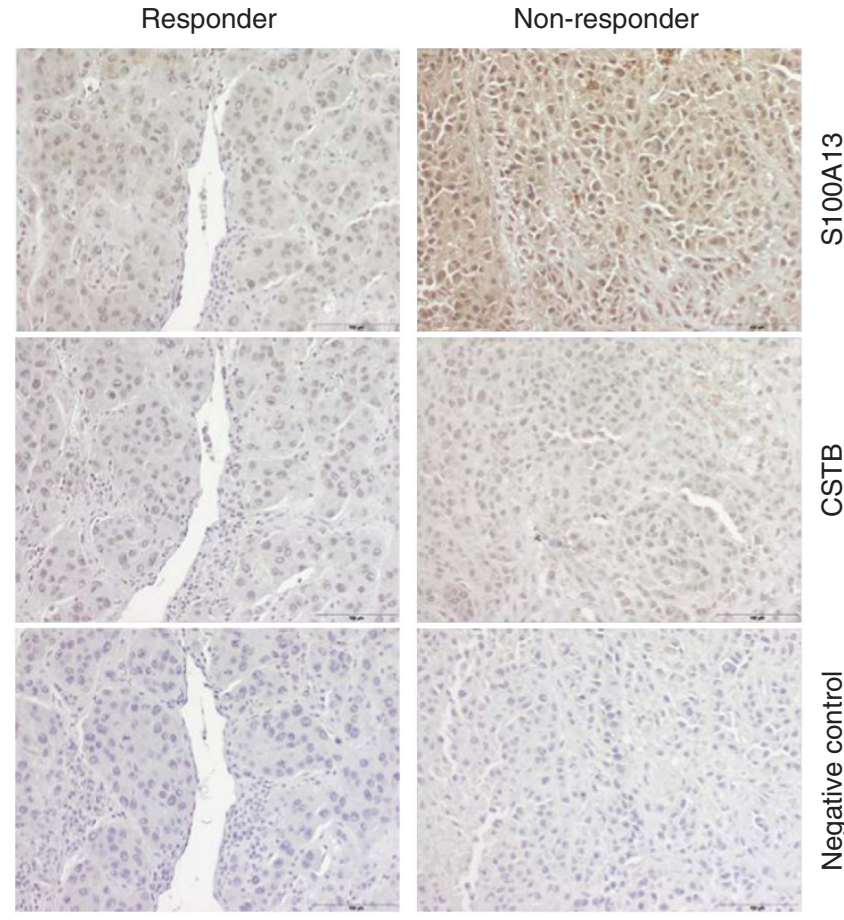

Figure 2. Immunohistochemistry. Representative images of metastases from DTIC/TMZ responders and non-responders, stained with antibodies for S100A13, CSTB or negative control without any primary antibody.

Table 3. Cytoplasmic expression of S100A13 and CSTB in pre-treatment tumour biopsies from DTIC/TMZ responders (R) and non-responders (NR)

\begin{tabular}{|c|c|c|}
\hline & Positive cytoplasmic staining (\%) & Fisher's exact test $(P)$ \\
\hline \multicolumn{3}{|c|}{ S100A13 } \\
\hline $\begin{array}{l}\mathrm{R} \\
\mathrm{NR}\end{array}$ & $\begin{array}{r}4 / 16(25) \\
21 / 32(66)\end{array}$ & 0.013 \\
\hline \multicolumn{3}{|c|}{ CSTB } \\
\hline $\begin{array}{l}\mathrm{R} \\
\mathrm{NR}\end{array}$ & $\begin{array}{l}5 / 16(31) \\
7 / 34(21)\end{array}$ & 0.49 \\
\hline
\end{tabular}

other alkylating agents has been studied by other proteomics methods mainly in glioma samples and cell lines (refer to the study by Suk (2012) for a review). Resistance to TMZ or other chemotherapeutic agents (vindesine, cisplatin, fotemustine or etoposide) has also been investigated by gene expression microarray analyses (Augustine et al, 2009) and proteomics (Sinha et al, 2003; Paulitschke et al, 2013) in melanoma cell lines. Interestingly, members of the top canonical pathway identified in our study, 'Signalling by Rho Family GTPases', are among the strongest chemoresistance candidates also in melanoma cell lines treated with other anticancer agents (Augustine et al, 2009). Additional functional categories from other studies that overlap with our results include potential druggable candidate pathways, namely heat shock proteins and proteasomal proteins (Sinha et al, 2003; Suk, 2012).

The correlation between S100A13 expression and DTIC/TMZ resistance detected in the global proteomics analysis was confirmed by immunohistochemistry in an extended set of pre-treatment melanoma tumours. The calcium binding S100 family proteins are involved in several intracellular processes such as phosphorylation regulation of proteins, cell differentiation and cell growth and cytoskeleton dynamics (Donato et al, 2013). They are reported to 
be over-expressed in several cancer types, including melanoma tumour cells (Hardesty et al, 2011) and in gliomas (Schwartz et al, 2005). S100A13 has previously been suggested to be an angiogenic marker for melanoma and astrocytic gliomas (Landriscina et al, 2006; Massi et al, 2010) and also to be involved in the invasiveness of lung cancer cell lines (Pierce et al, 2008).

There could be several potential mechanisms by which S100A13 influences chemoresistance: in tumours, S100A13 could be a marker for vessel density and on a cellular level, S100A13 regulates secretion of FGF1 (Cao et al, 2010) and IL1A (Mohan and Yu, 2011). In addition to its proposed role in angiogenesis and invasion, S100A13 is also involved in several key signalling pathways with relevance to cell cycle progression and differentiation, including cytokine and NFKB signalling, supporting that S100A13 may be related to increased aggressiveness of melanoma tumours (Hsieh et al, 2004; Massi et al, 2010). Our results are also in line with the reported positive correlation between S100A13 mRNA levels, risk of relapse and status of melanoma patients at follow-up (Massi et al, 2010). The elevated expression of S100A proteins, including S100A13, in melanoma cell lines resistant to cisplatin (Paulitschke et al, 2013) indicate that S100A13 could have a more general role in melanoma chemoresistance, not specific for DTIC/TMZ.

The second candidate protein that was investigated in the larger material was CSTB. This endogenous inhibitor of cathepsins $1, \mathrm{~h}, \mathrm{~b}$ and papain is thought to be involved in the protection against lysosomal protease leakage, and has been suggested to be a marker for more advanced disease and bad prognosis in various forms of cancer (Kos et al, 2000; Werle et al, 2006; Ghashenko et al, 2013). However, our immunohistochemistry results did not support the hypothesis of CSTB playing a significant role in DTIC/TMZ resistance.

We have previously shown that the main melanogenesis regulator, the transcription factor MITF, is associated with resistance to DTIC/TMZ (Hertzman Johansson et al, 2013) and the relatively high proportion of MITF-regulated proteins among the candidates identified in this study supports this finding.

In summary, our results showed significantly higher cytoplasmic levels of the S100A13 protein in pre-treatment tumour biopsies from DTIC/TMZ non-responders compared with responders. Thus, low levels or no expression of S100A13 may be one of the key predictive markers to identify melanoma patients responding to DTIC/TMZ therapy. Further in-depth studies on how S100A13 regulates response to DTIC/TMZ are needed and the finding should be validated in larger independent sets of tumour samples from melanoma patients.

\section{ACKNOWLEDGEMENTS}

This work was supported by grants from the European Commission (CHEMORES, LSHC CT-2007-037665), Karolinska Institutet funds, the Cancer Research Funds of Radiumhemmet and the Swedish Cancer Society.

\section{REFERENCES}

Augustine CK, Yoo JS, Potti A, Yoshimoto Y, Zipfel PA, Friedman HS, Nevins JR, Ali-Osman F, Tyler DS (2009) Genomic and molecular profiling predicts response to temozolomide in melanoma. Clin Cancer Res 15(2): 502-510.

Balch CM, Buzaid AC, Soong SJ, Atkins MB, Cascinelli N, Coit DG, Fleming ID, Gershenwald JE, Houghton Jr A, Kirkwood JM, McMasters KM, Mihm MF, Morton DL, Reintgen DS, Ross MI, Sober A, Thompson JA, Thompson JF (2001) Final version of the American Joint Committee on Cancer staging system for cutaneous melanoma. J Clin Oncol 19: 3635-3648.
Balch A, Soong SJ, Atkins MB, Buzaid AC, Cascinelli N, Coit DG, Fleming ID, Gershenwald JE, Houghton Jr A, Kirkwood JM, McMasters KM,

Mihm MF, Morton DL, Reintgen DS, Ross MI, Sober A, Thompson JA, Thompson JF (2004) An evidence-basedstaging system for cutaneous melanoma. CA Cancer J Clin 54: 131-149(quiz 182-184).

Busch C, Geisler J, Lillehaug JR, Lønning PE (2010) MGMT expression levels predict disease stabilisation, progression-free and overall survival in patients with advanced melanomas treated with DTIC. Eur J Cancer 46(11): 2127-2133.

Cao R, Yan B, Yang H, Zu X, Wen G, Zhong J (2010) Effect of human S100A13 gene silencing on FGF-1 transportation in human endothelial cells. J Formos Med Assoc 109(9): 632-640.

Chapman PB, Hauschild A, Robert C et al. (2011) Improved survival with vemurafenib in melanoma with BRAF V600E mutation. N Engl J Med 364: 2507-2516.

Chen KG, Valencia JC, Lai B, Zhang G, Paterson JK, Rouzaud F et al. (2006) Melanosomal sequestration of cytotoxic drugs contributes to the intractability of malignant melanomas. Proc Natl Acad Sci USA 103: 9903-9907.

Donato R, Cannon BR, Sorci G, Riuzzi F, Hsu K, Weber DJ, Geczy CL (2013) Functions of S100 proteins. Curr Mol Med 13(1): 24-57.

Erdmann F, Lortet-Tieulent J, Schuz J, Zeeb H, Greinert R, Breitbart EW, Bray F (2013) International trends in the incidence of malignant melanoma 1953-2008-are recent generations at higher or lower risk? Int J Cancer 132: 385-400.

Eriksson L, Antti H, Gottfries J, Holmes E, Johansson E, Lindgren F, Long I, Lundstedt T, Trygg J, Wold S (2004) Using chemometrics for navigating in the large data sets of genomics, proteomics, and metabonomics (gpm). Anal Bioanal Chem 380(3): 419-429.

Flaherty KT, Infante JR, Daud A, Gonzalez R, Kefford RF, Sosman J, Hamid O, Schuchter L, Cebon J, Ibrahim N, Kudchadkar R, Burris 3rd HA, Falchook G, Algazi A, Lewis K, Long GV, Puzanov I, Lebowitz P, Singh A, Little S, Sun P, Allred A, Ouellet D, Kim KB, Patel K, Weber J (2012a) Combined BRAF and MEK inhibition in melanoma with BRAF V600 mutations. N Engl J Med 367: 1694-1703.

Flaherty KT, Robert C, Hersey P, Nathan P, Garbe C, Milhem M, Demidov LV, Hassel JC, Rutkowski P, Mohr P, Dummer R, Trefzer U, Larkin JM, Utikal J, Dreno B, Nyakas M, Middleton MR, Becker JC, Casey M, Sherman LJ, Wu FS, Ouellet D, Martin AM, Patel K, Schadendorf D. METRIC Study Group (2012b) Improved survival with MEK inhibition in BRAF-mutated melanoma. N Engl J Med 367: 107-114.

Gashenko EA, Lebedeva VA, Brak IV, Tsykalenko EA, Vinokurova GV, Korolenko TA (2013) Evaluation of serum procathepsin B, cystatin B and cystatin $\mathrm{C}$ as possible biomarkers of ovarian cancer. Int J Circumpolar Health 5: 72.

Gogas HJ, Kirkwood JM, Sondak VK (2007) Chemotherapy for metastatic melanoma: time for a change? Cancer 109: 455-464.

Hardesty WM, Kelley MC, Mi D, Low RL, Caprioli RM (2011) Protein signatures for survival and recurrence in metastatic melanoma. J Proteomics 74(7): 1002-1014.

Hauschild A, Grob JJ, Demidov LV, Jouary T, Gutzmer R, Millward M, Rutkowski P, Blank CU, Miller Jr WH, Kaempgen E, Martín-Algarra S, Karaszewska B, Mauch C, Chiarion-Sileni V, Martin AM, Swann S, Haney P, Mirakhur B, Guckert ME, Goodman V, Chapman PB (2012) Dabrafenib in BRAF-mutated metastatic melanoma: a multicentre, open-label, phase 3 randomised controlled trial. Lancet 380: 358-365. Hertzman Johansson C, Azimi A, Pernemalm M, Pawitan Y, Frostvik Stolt M, Lazar V, Lundeberg J, Lehtiö J, Egyházi S, Hansson. J (2012) Proteomics and gene expression profiling of melanoma chemotherapy response in tumors. WIN 2012 Symposium, Paris, June 28-29, 2012. Ann Oncol 23(suppl 5): 27.

Hertzman Johansson C, Azimi A, Frostvik Stolt M, Shojaee S, Wiberg H, Grafström E, Hansson J, Egyházi Brage S (2013) Association of MITF and other melanosome-related proteins with chemoresistance in melanoma tumors and cell lines. Melanoma Res; e-pub ahead of print 5 August 2013.

Hill 2nd GJ, Krementz ET, Hill HZ (1984) Dimethyl triazeno imidazole carboxamide and combination therapy for melanoma. IV. Late results after complete response to chemotherapy (Central Oncology Group protocols 7130, 7131 and 7131A). Cancer 53: 1299-1305.

Hodi FS, O’Day SJ, McDermott DF, Weber RW, Sosman JA, Haanen JB, Gonzalez R, Robert C, Schadendorf D, Hassel JC, Akerley W, van den Eertwegh AJ, Lutzky J, Lorigan P, Vaubel JM, Linette GP, Hogg D, Ottensmeier CH, Lebbé C, Peschel C, Quirt I, Clark JI, Wolchok JD, Weber JS, Tian J, Yellin MJ, Nichol GM, Hoos A, Urba WJ (2010) 
Improved survival with ipilimumab in patients with metastatic melanoma. $N$ Engl J Med 363: 711-723.

Hoek KS, Schlegel NC, Eichhoff OM, Widmer DS, Praetorius C, Einarsson SO, Valgeirsdottir S, Bergsteinsdottir K, Schepsky A, Dummer R, Steingrimsson E (2008) Novel MITF targets identified using a two-step DNA microarray strategy. Pigment Cell Melanoma Res 21(6): 665-676.

Hsieh HL, Schäfer BW, Weigle B, Heizmann CW (2004) S100 protein translocation in response to extracellular S100 is mediated by receptor for advanced glycation endproducts in human endothelial cells. Biochem Biophys Res Commun 316(3): 949-959.

Kim C, Lee CW, Kovacic L, Shah A, Klasa R, Savage KJ (2010) Long-term survival in patients with metastatic melanoma treated with DTIC or temozolomide. Oncologist 15: 765-771.

Kos J, Krasovec M, Cimerman N, Nielsen HJ, Christensen IJ, Brünner N (2000) Cysteine proteinase inhibitors stefin A, stefin B, and cystatin C in sera from patients with colorectal cancer: relation to prognosis. Clin Cancer Res 6(2): 505-511.

Landriscina M, Schinzari G, Di Leonardo G, Quirino M, Cassano A, D’Argento E, Lauriola L, Scerrati M, Prudovsky I, Barone C (2006) S100A13, a new marker of angiogenesis in human astrocytic gliomas. J Neurooncol 80(3): 251-259.

Ma S, Egyházi S, Ueno T, Lindholm C, Kreklau EL, Stierner U, Ringborg U, Hansson J (2003) O6-methylguanine-DNA-methyltransferase expression and gene polymorphisms in relation to chemotherapeutic response in metastatic melanoma. Br J Cancer 89(8): 1517-1523.

Massi D, Landriscina M, Piscazzi A, Cosci E, Kirov A, Paglierani M, Di Serio C, Mourmouras V, Fumagalli S, Biagioli M, Prudovsky I, Miracco C, Santucci M, Marchionni N, Tarantini F (2010) S100A13 is a new angiogenic marker in human melanoma. Mod Pathol 23(6): 804-813.

Menzies AM, Long GV (2013) Recent advances in melanoma systemic therapy. BRAF inhibitors, CTLA4 antibodies and beyond. Eur J Cancer 49(15): 3229-3241.

Middleton MR, Grob JJ, Aaronson N, Fierlbeck G, Tilgen W, Seiter S, Gore M, Aamdal S, Cebon J, Coates A, Dreno B, Henz M, Schadendorf D, Kapp A, Weiss J, Fraass U, Statkevich P, Muller M, Thatcher N (2000) Randomized phase III study of temozolomide versus dacarbazine in the treatment of patients with advanced metastatic malignant melanoma. J Clin Oncol 18: $158-166$.

Mohan SK, Yu C. The IL1alpha-S100A13 heterotetrameric complex structure: a component in the non-classical pathway for interleukin lalpha secretion (2011) J Biol Chem 286(16): 14608-14617.

Patel PM, Suciu S, Mortier L, Kruit WH, Robert C, Schadendorf D, Trefzer U, Punt CJ, Dummer R, Davidson N, Becker J, Conry R, Thompson JA,
Hwu WJ, Engelen K, Agarwala SS, Keilholz U, Eggermont AM, Spatz A. EORTC Melanoma Group (2011) Extended schedule, escalated dose temozolomide versus dacarbazine in stage IV melanoma: final results of a randomised phase III study (EORTC 18032). Eur J Cancer 47(10): 1476-1483.

Paulitschke V, Haudek-Prinz V, Griss J, Berger W, Mohr T, Pehamberger H, Kunstfeld R, Gerner C (2013) Functional classification of cellular proteome profiles support the identification of drug resistance signatures in melanoma cells. J Proteome Res 12(7): 3264-3276.

Pierce A, Barron N, Linehan R, Ryan E, O’Driscoll L, Daly C, Clynes M (2008) Identification of a novel, functional role for S100A13 in invasive lung cancer cell lines. Eur J Cancer 44(1): 151-159.

Schwartz SA, Weil RJ, Thompson RC, Shyr Y, Moore JH, Toms SA, Johnson MD, Caprioli RM (2005) Proteomic-based prognosis of brain tumor patients using direct-tissue matrix-assisted laser desorption ionization mass spectrometry. Cancer Res 65(17): 7674-7681.

Sinha P, Poland J, Kohl S, Schnölzer M, Helmbach H, Hütter G, Lage H, Schadendorf D (2003) Study of the development of chemoresistance in melanoma cell lines using proteome analysis. Electrophoresis 24(14): 2386-2404.

Strub T, Giuliano S, Ye T, Bonet C, Keime C, Kobi D, Le Gras S, Cormont M, Ballotti R, Bertolotto C, Davidson I (2011) Essential role of microphthalmia transcription factor for DNA replication, mitosis and genomic stability in melanoma. Oncogene 30(20): 2319-2332.

Suk K (2012) Proteomic analysis of glioma chemoresistance. Curr Neuropharmacol 10(1): 72-79.

Werle B, Schanzenbächer U, Lah TT, Ebert E, Jülke B, Ebert W, Fiehn W, Kayser K, Spiess E, Abrahamson M, Kos J (2006) Cystatins in non-small cell lung cancer: tissue levels, localization and relation to prognosis. Oncol Rep 16(4): 647-655.

Xie T, Nguyen T, Hupe M, Wei ML (2009) Multidrug resistance decreases with mutations of melanosomal regulatory genes. Cancer Res 69: 992-999.

Zhang J, Stevens MFG, Bradshaw TD (2012) Temozolomide: Mechanisms of action, repair and resistance. Curr Mol Pharmacol 5: 102-114.

This work is published under the standard license to publish agreement. After 12 months the work will become freely available and the license terms will switch to a Creative Commons AttributionNonCommercial-Share Alike 3.0 Unported License.

Supplementary Information accompanies this paper on British Journal of Cancer website (http://www.nature.com/bjc) 